\title{
Sol-gel-derived photonic structures handling erbium ions luminescence
}

\author{
A. Lukowiak - A. Chiappini - A. Chiasera - D. Ristic - I. Vasilchenko • \\ C. Armellini - A. Carpentiero - S. Varas - G. Speranza - S. Taccheo - S. Pelli • \\ I. K. Battisha - G. C. Righini · W. Strek · M. Ferrari
}

Received: 15 January 2014 / Accepted: 23 May 2014 / Published online: 8 June 2014

(C) The Author(s) 2014. This article is published with open access at Springerlink.com

\begin{abstract}
The sol-gel technique is a very flexible, relatively simple, and low-cost method to fabricate many different innovative photonic structures characterized by specific functionalities. During synthesis, starting from the molecular level, compounds or composites with well controlled composition can be obtained as thin films, powders or monoliths. These materials can be used to prepare such structures as waveguides, photonic crystals, coatings, and bulk glasses including spheres, rings and other geometries exploited in optical resonators fabri-
\end{abstract}

A. Lukowiak $(\varangle) \cdot$ A. Chiappini - A. Chiasera - D. Ristic · I. Vasilchenko - C. Armellini ·

A. Carpentiero $\cdot$ S. Varas $\cdot$ G. Speranza $\cdot$ M. Ferrari

IFN - CNR CSMFO Lab., Via alla Cascata 56/C Povo, 38123 Trento, Italy

e-mail: A.Lukowiak@int.pan.wroc.pl

A. Lukowiak · W. Strek

Institute of Low Temperature and Structure Research, PAS, Okolna 2, 50-422 Wrocław, Poland

D. Ristic

Institut Ruđ er Bošković, Bijenička cesta 54, 10000 Zagreb, Croatia

I. Vasilchenko

Dipartimento di Fisica, Università di Trento, via Sommarive 14, Povo, 38123 Trento, Italy

C. Armellini · G. Speranza

FBK Center for Materials and Microsystems, via Sommarive 18, Povo 38123, Trento, Italy

S. Taccheo

College of Engineering, Swansea University, Singleton Park, Swansea, UK

S. Pelli · G. C. Righini

IFAC - CNR, MiPLab, Via Madonna del Piano 10, 50019 Sesto Fiorentino, Italy

I. K. Battisha

National Research Center, 12622 Dokki, Giza, Egypt

G. C. Righini

Museo Storico della Fisica e Centro di Studi e Ricerche Enrico Fermi, P.zza Viminale 1, 00184 Rome, Italy 
cation. This article presents some results obtained by the authors in the field of the sol-gelderived photonic structures. To emphasise the scientific and technological interest in this kind of systems and the versatility of the sol-gel route, the glass-based nano and micrometer scale range systems are discussed. Particularly, the following systems are described: silica-hafnia glass and glass-ceramic planar waveguides, nanosized tetraphosphates, and silica colloidal crystals. The attention is focused on the spectroscopic properties of $\mathrm{Er}^{3+}$-activated materials that due to the light emission can be used in the integrated optics area covering application in sensing, biomedical diagnostic, energy conversion, telecommunication, lighting, and photon management.

Keywords Waveguide $\cdot$ Photonic crystal $\cdot$ Nanocrystals $\cdot$ Spectroscopy $\cdot$ Structure

\section{Introduction}

The sol-gel processing due to the advantages in terms of design, form, composition, structure, and optical properties are successfully applied for fabrication of photonic structures. Silicabased glasses have already had a wide range of application (Iraj Najafi 1998; Stein and Schroden 2001; Gan and Xu 2006). However, not only amorphous systems can be synthesized by the sol-gel route. Recently, of specific interest are glass-ceramic materials that combine properties of glasses and crystals (Berneschi et al. 2011). The sol-gel-based modified Pechini method (Pechini 1967) enables synthesis of crystalline nanopowders useful for preparation of colloidal solution, nanoceramic, or composites. Finally, rare earth (RE) doped glasses, glass-ceramics or nanocrystals can be used as active building blocks of integrated optics components.

The aim of this work is to present a versatility of the sol-gel technique for preparation of different kinds of materials that can be used as photonic structures. We focus on RE-doped systems in both amorphous and crystalline matrices.

First, planar structures based on the $\mathrm{Er}^{3+}$-doped silica-hafnia system is briefly discussed. Using a suitable top-down process, it is possible to obtain glass-ceramic planar waveguides with low attenuation coefficient. Depending on the structure of the oxide layer, the luminescent properties of the material can be tailored to some extent.

The properties of nanocrystalline tetraphosphates are also presented. Polyphosphates are very attractive hosts for RE ions allowing to introduce high concentration of luminescent ions without effective concentration quenching. Moreover, small dimension of the particles allows to obtain composite layers or nanoceramics.

A third example concerns realization and characterization of three-dimensional (3D) photonic crystals activated with $\mathrm{Er}^{3+}$ ions. These systems, constituted by regular structure of submicrometer periodicity, are useful for controlling, manipulating, and localizing the propagation of light and nowadays can be applied in different fields such as random laser devices and optical sensors.

\section{Silica-hafnia planar waveguides}

Erbium doped planar waveguides can be used for signal amplification (at a wavelength of $1.55 \mu \mathrm{m}$ ) in the same way as in the erbium doped fibre amplifiers (EDFAs). However, the relatively small dimension in erbium doped waveguide amplifiers (EDWAs) exacts higher concentration of active ions as compared to the fibre device. In glasses, high RE concentration 
leads to the formation of ions physical clusters and to the reduced amplifier efficiency due to the energy transfer between the ions. To maintain the high gain, higher $\mathrm{Er}^{3+}$ concentration in the glassy matrix can be achieved by co-doping with phosphorous or aluminium ions (Badr et al. 2011). Another route is to prepare glass-ceramics, where a glass host is loaded with a crystalline phase containing the active ions. This kind of nanocomposites combines the properties of the glass, such as transparency, mechanical and chemical stability, with a crystallike environment for the RE ions that ensures higher absorption and emission cross-sections and reduced non-radiative relaxation, this latter depending on the nanocrystals (Jestin et al. 2007; Berneschi et al. 2011).

The $1 \mathrm{~mol} \% \mathrm{Er}^{3+}$-doped silica glass with $30 \mathrm{~mol} \%$ of $\mathrm{HfO}_{2}\left(70 \mathrm{SiO}_{2}-30 \mathrm{HfO}_{2}\right)$ was synthesized using tetraethyl orthosilicate $\left(\mathrm{Si}\left(\mathrm{OC}_{2} \mathrm{H}_{5}\right)_{4}\right)$ and hafnium(IV) oxychloride $\left(\mathrm{HfOCl}_{2}\right)$ as silica and hafnia precursors. To obtain a sol, the precursors were mixed with proper amount of water, ethanol, and hydrochloric acid. The planar waveguide was prepared on vitreous silica substrates by a multistep dip-coating process. The fully densified layers were obtained after heat treatment in air at $900^{\circ} \mathrm{C}$ for $5 \mathrm{~min}$. To prepare glass-ceramics, the films were successively heat treated at $1,000{ }^{\circ} \mathrm{C}$ for $30 \mathrm{~min}$. The fabrication details can be found in (Zampedri et al. 2004).

The X-ray diffraction (XRD) and high-resolution transmission electron microscopy (HRTEM) analyses showed that samples annealed at $900^{\circ} \mathrm{C}$ were amorphous whereas higher temperature led to the growth of nanocrystallites in the amorphous matrix (Minati et al. 2009). The formation of tetragonal $\mathrm{HfO}_{2}$ nanocrystals with dimensions of 4-6 nm was observed. The crystallites were small enough to avoid scattering losses, therefore, both the glass and the glass-ceramics layers were transparent with low optical losses (about $1 \mathrm{~dB} / \mathrm{cm} @ 1,542 \mathrm{~nm}$ ). The waveguides had thickness of about $1 \mu \mathrm{m}$ and supported at least two TE/TM modes in the visible range and one mode in the NIR (1.3 and $1.5 \mu \mathrm{m})$.

X-ray photoelectron spectroscopy (XPS) (Minati et al. 2007) and X-ray absorption fine structure (EXAFS) (Afifi et al. 2007) measurements gave more information about the structure. Hafnia was well dispersed in the silica matrix and no phase separation was observed. $\mathrm{Er}^{3+}$ ions remained incorporated in $\mathrm{HfO}_{2}$ nanocrystals and probably substituted the $\mathrm{Hf}^{4+}$ ions in the crystalline lattice.

The difference in photoluminescence properties between the $\mathrm{Er}^{3+}$-doped $\mathrm{SiO}_{2}-\mathrm{HfO}_{2}$ glass and glass-ceramic could be also easily observed (Jestin et al. 2007; Berneschi et al. 2010). The emission bands of the sample annealed at lower temperature were broad as usually observed in amorphous matrices. However, the glass-ceramic layers showed the typical properties of $\mathrm{Er}^{3+}$ in nanocrystals such as narrowing of the emission bands with well resolved Stark components and lengthening of the measured lifetime for the ${ }^{4} \mathrm{I}_{13 / 2} \rightarrow{ }^{4} \mathrm{I}_{15 / 2}$ transition (from $2 \mathrm{~ms}$ in glass to $>5 \mathrm{~ms}$ in glass-ceramic).

\section{Nanocrystalline tetraphosphates}

Synthesis of powders through the sol-gel route with the citric acid and ethylene glycol (Pechini method) allows to obtain nanocrystalline materials. This technique can be used to prepare among others powders of RE-doped tetraphosphates. These matrices are interesting for lanthanides ions ( $\mathrm{Ln}$ ) due to the structure where lanthanides dodecahedra, $\mathrm{LnO}_{8}$, are separated and long Ln-Ln distance (in the range of $5 \AA$ ) occurs. Different lanthanides ions can be introduced into the structure with the concentration up to $100 \mathrm{~mol} \%$ (e.g. $\left.\operatorname{LiEr}\left(\mathrm{PO}_{3}\right)_{4}\right)$.

In the present study, $\mathrm{Er}^{3+}$-doped lithium tetraphosphates with general formula $\operatorname{LiLn}_{1-x} \mathrm{Er}_{x}$ $\left(\mathrm{PO}_{3}\right)_{4}$, where $x$ is in the range of $1-100 \mathrm{~mol} \%$, were prepared. The scheme of the powder 


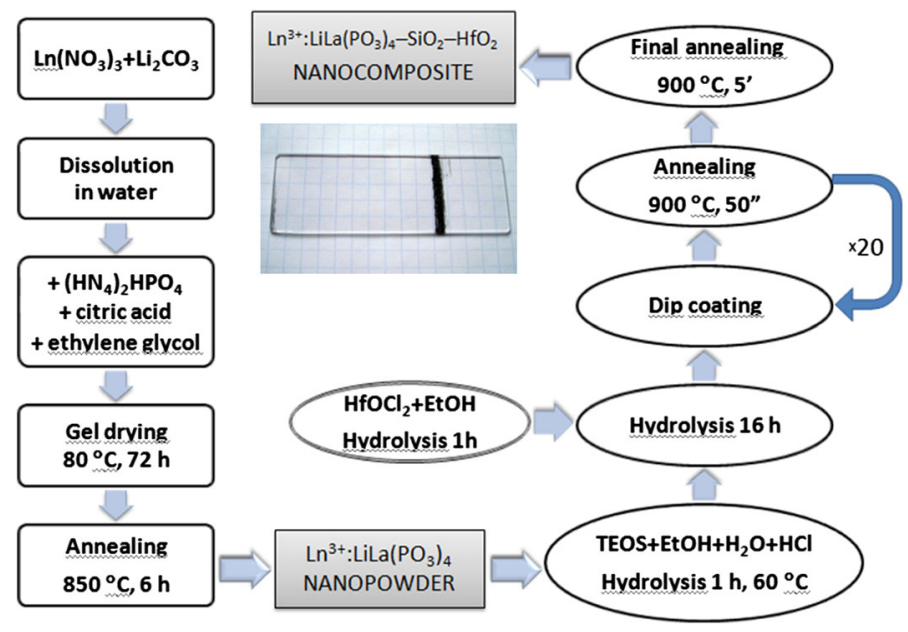

Fig. 1 Scheme of the synthesis of powdered tetraphosphates and their nanocomposites with $\mathrm{SiO}_{2}-\mathrm{HfO}_{2}$ glass; the micrograph presents $0.8 \mu$ m-thick composite layer on $\mathrm{SiO}_{2}$ substrate

Fig. 2 XRD and TEM picture of $1 \% \mathrm{Er}^{3+}: \mathrm{LiLa}\left(\mathrm{PO}_{3}\right)_{4}$

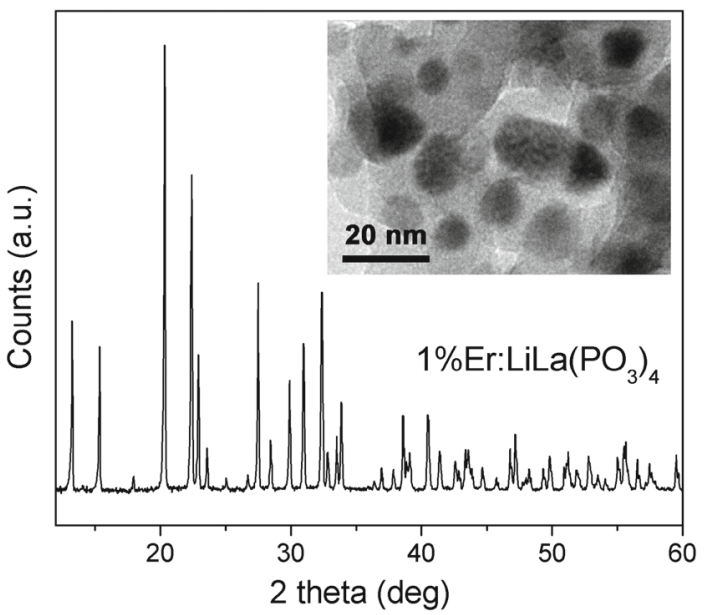

preparation is shown in Fig. 1 and the detailed synthesis protocol can be found in (Wiglusz et al. 2011). The XRD analysis (Fig. 2) has shown the monoclinic structure with a space group $\mathrm{C} 12 / \mathrm{c} 1$ for all the samples. The average size of nanocrystallites was calculated using the Scherrer equation and was equal to about $35 \mathrm{~nm}$. The HR-TEM picture (inset in Fig. 2), has shown that the smallest grains had a diameter of $10 \mathrm{~nm}$.

The luminescence spectra of the samples with $\mathrm{Er}^{3+}$ molar concentration from 1 to $100 \%$ upon $532 \mathrm{~nm}$ excitation are presented in Fig. $3 \mathrm{a}$ (after normalization to the observed most intense Raman band at $567 \mathrm{~nm}$ that is equal to Raman shift at $1,175 \mathrm{~cm}^{-1}$ ). The emission bands at around $550 \mathrm{~nm}$ were assigned to the ${ }^{4} \mathrm{~S}_{3 / 2} \rightarrow{ }^{4} \mathrm{I}_{15 / 2}$ transition. The intensities of these bands, as compared to the Raman lines, linearly increased with the increase of the $\mathrm{Er}^{3+}$ content (Fig. 3b). This result and the luminescence kinetics studies for similar samples doped with $\mathrm{Eu}^{3+}$ (Lukowiak et al. 2014), indicated that in the tetraphosphate matrices the concentration quenching is efficiently reduced. 

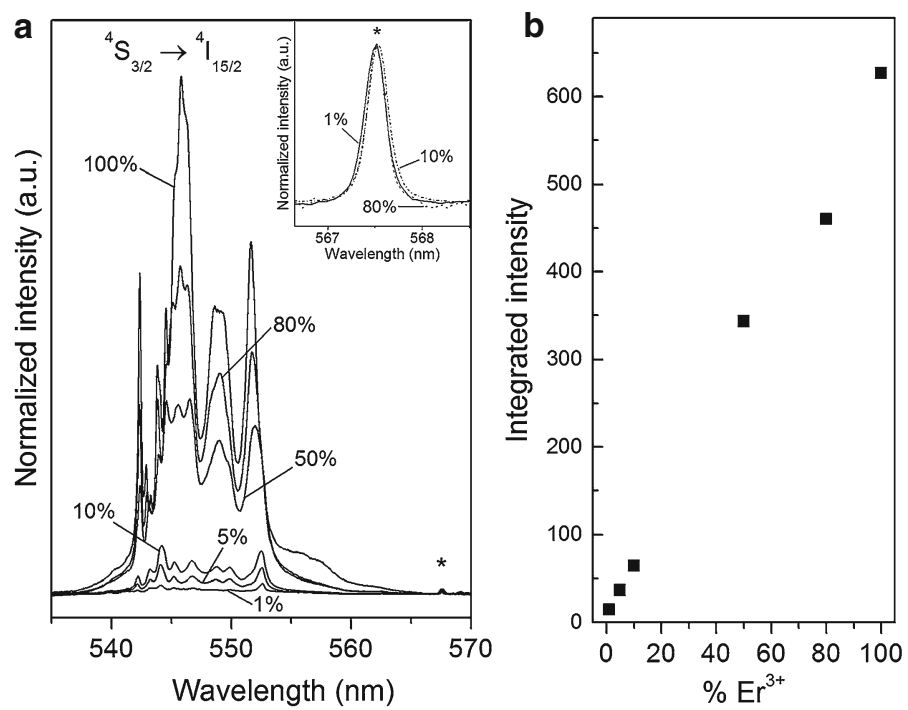

Fig. 3 a Emission spectra of $\mathrm{Er}^{3+}: \mathrm{LiLa}\left(\mathrm{PO}_{3}\right)_{4}$ powders $(\lambda$ exc $=532 \mathrm{~nm})$ normalized to Raman band (marked with an asterisk and shown in the inset); $\mathbf{b}$ intensity increase of ${ }^{4} \mathrm{~S}_{3 / 2} \rightarrow{ }^{4} \mathrm{I}_{15 / 2}$ transition with $\mathrm{Er}^{3+}$ concentration

The relatively small dimensions of nanocrystals enables fabrication of transparent nanocomposite layers (Lukowiak et al. 2014) or ceramics (Bregiroux et al. 2006; Zhao et al. 2010). For example, silica-hafnia glass matrix can be used for thin film preparation because, as it was presented in the Sect. 2, this system is suitable for RE doping and fabrication of glass or glass-ceramic planar waveguides. Following the preparation protocol presented in Fig. 1, transparent coatings can be prepared. During the gel formation, the nanoparticles are embedded into the amorphous matrix that is also reflected in the luminescence spectra (Lukowiak et al. 2014). This kind of structures with proper RE ions could find application as down- or up-converters to improve solar cell efficiencies.

\section{$4 \mathrm{Er}^{3+}$-activated silica colloidal crystal structures}

The realization of 3D photonic crystals by means of sol-gel route is based on the assembly of monosize nanoparticles into highly ordered 3D nanostructures called colloidal crystals or opals. The periodic variation of the refractive index produces a band of photon frequencies which is not allowed to propagate within the ordered nanostructure, and its wavelength position can be ascribed using the modified Bragg Law: $\lambda=2 \cdot d_{111} \cdot n_{\text {eff }}$, where $d_{111}$ corresponds to the interplanar distance and $n_{e f f}$ is the effective refractive index (Chiappini et al. 2011). In particular, as evidenced by the Bragg Law, is possible to tailor the properties of the system (e.g. the position of the stop band) just modifying its structural features such as interplanar distance (Chiappini et al. 2013, 2011) or effective refractive index. The variation of $n_{\text {eff }}$ can occur changing the type of material that constitutes the network of the system (Chiappini et al. 2011) or creating structures with different surface area (filling factor). In this last contest, the versatility of the sol-gel approach permits to realize both direct and inverse systems (Chiappini et al. 2009). In Fig. 4, there is reported a SEM image showing the top 


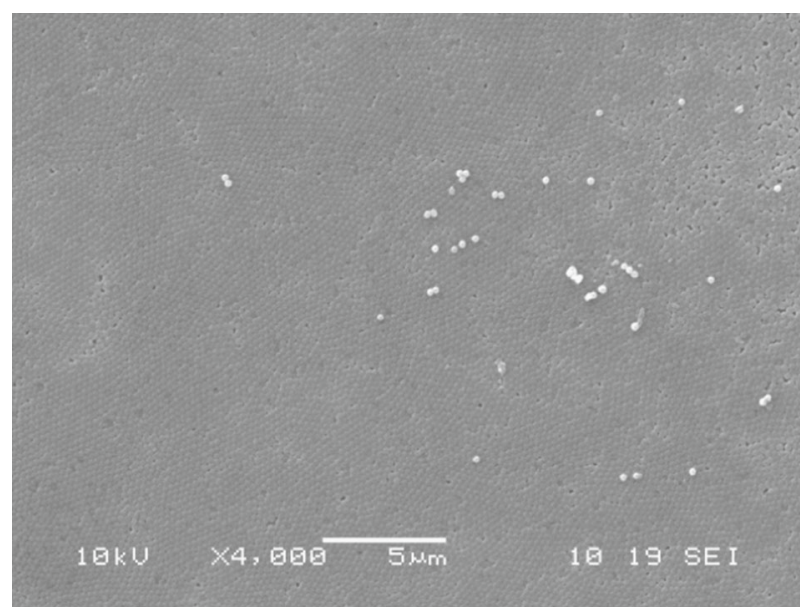

Fig. 4 SEM image related to $<111>$ facet of direct opal constituted by monosize core-shell NPs activated with $\mathrm{Er}^{3+}$ ions

Fig. 5 Photoluminescence spectrum of ${ }^{4} \mathrm{I}_{13 / 2} \rightarrow{ }^{4} \mathrm{I}_{15 / 2}$ of inverse silica opal activated with $\mathrm{Er}^{3+}$ upon excitation at $514.5 \mathrm{~nm}$

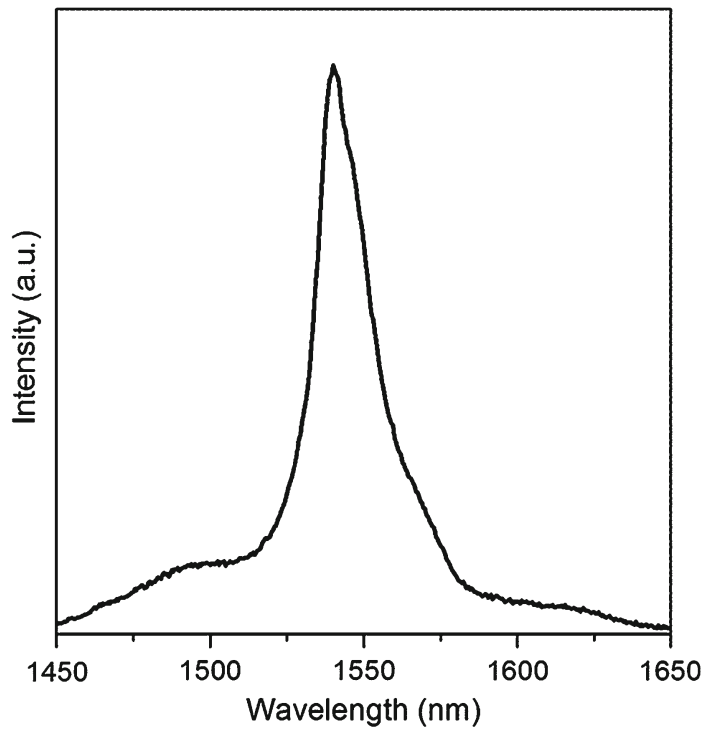

view of a direct structure constituted by silica nanoparticles (NPs) activated with $\mathrm{Er}^{3+}$ ions in the external shell (Chiappini et al. 2011).

Analysing Fig. 4 is evident that the NPs are well-ordered in a triangular lattice that can be associated to the $<111>$ planes of a fcc crystalline structure. On the other hand, an inverse opal structure can be represented as a negative replica of the direct one. In fact its realization is obtained starting from a direct opal, infiltrating the air voids with a stable dielectric solution (e.g. activated with $\mathrm{Er}^{3+}$ ions), and then removing the NPs (e.g. polystyrene balls) that constitute the colloidal crystal (Chiappini et al. 2009); in this case the direct opal is used only as a sacrificial template.

The spectroscopic assessment of direct and inverse colloidal crystals has been performed investigating the photoluminescence associated to the ${ }^{4} \mathrm{I}_{13 / 2} \rightarrow{ }^{4} \mathrm{I}_{15 / 2}$ transition of $\mathrm{Er}^{3+}$ ions, 
as well as estimating the quantum efficiency $(\mathrm{QE})$ of the systems measuring the lifetime. In Fig. 5, there is shown the emission spectrum in the NIR region of the inverse system upon excitation at $514 \mathrm{~nm}$. In particular it is possible to observe a main emission peak centred at $1,540 \mathrm{~nm}$ and the presence of resolved Stark components, indicating that $\mathrm{Er}^{3+}$ ions occupy sites characterized by similar local environment so that inhomogeneous broadening is not so important with respect to the amount of the Stark splitting. The decay curve showed a singleexponential behaviour with a lifetime of $16.8 \pm 0.1 \mathrm{~ms}$. Considering the radiative lifetime $\tau_{\text {rad }}$ previously obtained (de Dood et al. 2001a, b; Slooff et al. 2000) for different $\mathrm{Er}^{3+}{ }_{\text {-silica }}$ systems (about $18 \mathrm{~ms}$ ) and defining the quantum efficiency as: $\mathrm{QE}=\frac{\tau_{m}}{\tau_{\text {rad }}}$, where $\tau_{\mathrm{m}}$ is the measured lifetime, an extremely high quantum efficiency can be determined for this type of system.

\section{Conclusions}

In the sol-gel technology, the possibility of starting from molecular precursors and elementary building blocks permits to tailor structures at the molecular level and to create new materials with enhanced performances. In the field of photonics, important physical effects as well as application in light management are studied for sol-gel-derived materials on the nano/micro scale structures such as photonic crystals and planar glass or glass-ceramic waveguides. The doping with RE ions allows to achieve active photonic structures allowing to handle the luminescence behaviour. Moreover, the spectroscopic properties can be used to determine the local environment of the RE showing if the ions are embedded in glass or glass-ceramic matrices.

Acknowledgments This research was performed in the framework of the MAE Significant Bilateral Project between Italy and Egypt "Smart optical nanostructures for green photonics" (2013-2015). A. L. thanks the Polish Ministry of Science and Higher Education for the financial support from the "Mobility Plus" Program.

Open Access This article is distributed under the terms of the Creative Commons Attribution License which permits any use, distribution, and reproduction in any medium, provided the original author(s) and the source are credited.

\section{References}

Afifi, N.D., Dalba, G., Rocca, F., Ferrari, M.: $\mathrm{Er}^{3+}$-activated $\mathrm{SiO}_{2}$-based glasses and glassceramics: from structure to optimization. Eur. J Glass Sci. Technol. B. Phys. Chem. Glasses 48, 229-234 (2007)

Badr, Y., Battisha, I.K., El Nahrawy, A.M.S., Elouadi, B., Kamal, M.: Physical study of thin film and monolithic nano-composites $\left[\mathrm{SiO}_{2}: 11 \mathrm{P}_{2} \mathrm{O}_{5}: 3 \mathrm{Al}_{2} \mathrm{O}_{3}:(1.2) \mathrm{Er}(1.2,1.8\right.$ and 3) Yb] prepared by sol-gel technique, planar waveguide and co-operative up-conversion. New J Glass Ceram. 1, 71-78 (2011)

Berneschi, S., Soria, S., Righini, G.C., Alombert-Goget, G., Chiappini, A., Chiasera, A., Jestin, Y., Ferrari, M., Guddala, S., Moser, E., Bhaktha, S.N.B., Boulard, B., Duverger Arfuso, C., Turrell, S.: Rare-earth-activated glass-ceramic waveguides. Opt. Mater. 32, 1644-1647 (2010)

Berneschi, S., Pelli, S., Boulard, B., Chiasera, A., Alombert-Goget, G., Duverger Arfuso, C., Ferrari, M.: Rare earth-activated glass-ceramic in planar format. Opt. Eng. 50, 071105-1/10 (2011)

Bregiroux, D., Lucas, S., Champion, E., Audubert, F., Bernache-Assollant, D.: Sintering and microstructure of rare earth phosphate ceramics $\mathrm{REPO}_{4}$ with RE = La, Ce or Y. J. Eur. Ceram. Soc. 26, 279-287 (2006)

Chiappini, A., Armellini, C., Chiasera, A., Jestin, Y., Ferrari, M., Moser, E., Nunzi Conti, G., Pelli, S., Retoux, R., Righini, G.C.: $\mathrm{Er}^{3+}$-activated sol-gel silica confined structures for photonic applications. Opt. Mater. 31, 1275-1279 (2009) 
Chiappini, A., Chiasera, A., Berneschi, S., Armellini, C., Carpentiero, A., Mazzola, M., Moser, E., Varas, S., Righini, G.C., Ferrari, M.: Sol-gel-derived photonic structures: fabrication, assessment, and application. J. Sol-Gel Sci. Technol. 60, 408-425 (2011)

Chiappini, A., Armellini, C., Carpentiero, A., Minati, L., Righini, G.C., Ferrari, M.: Solvent sensitive polymer composite structures. Opt. Mater. 36, 130-134 (2013)

de Dood, M.J.A., Slooff, L.H., Polman, A., Moroz, A., van Blaaderen, A.: Modified spontaneous emission in erbium-doped $\mathrm{SiO}_{2}$ spherical colloids. Appl. Phys. Lett. 79, 3585-3587 (2001a)

de Dood, M.J.A., Slooff, L.H., Polman, A., Moroz, A., van Blaaderen, A.: Local optical density of states in $\mathrm{SiO}_{2}$ spherical microcavities: theory and experiment. Phys. Rev. A 64, 33807 (2001b)

Gan, F., Xu, L. (eds.): Photonic Glasses. World Scientific Publishing, Singapore (2006)

Iraj Najafi, S. (ed.): Selected Papers on Sol-Gel for Photonics. SPIE Press, Bellingham (1998)

Jestin, Y., Armellini, C., Chiasera, A., Chiappini, A., Ferrari, M., Moser, E., Retoux, R., Righini, G.C.: Lowloss optical $\mathrm{Er}^{3+}$-activated glass-ceramics planar waveguides fabricated by bottom-up approach. Appl. Phys. Lett. 91, 071909 (2007)

Lukowiak, A., Wiglusz, R.J., Chiappini, A., Armellini, C., Battisha, I.K., Righini, G.C., Ferrari, M.: Structural and spectroscopic properties of $\mathrm{Eu}^{3+}$-activated nanocrystalline tetraphosphates loaded in silica-hafnia thin film. J. Non-Cryst. Solids (2014). doi:10.1016/j.jnoncrysol.2013.12.019

Minati, L., Speranza, G., Ferrari, M., Jestin, Y., Chiasera, A.: X-ray photoelectron spectroscopy of erbiumactivated-silica-hafnia waveguides. J. Non-Cryst. Solids 353, 502-505 (2007)

Minati, L., Speranza, G., Micheli, V., Ferrari, M., Jestin, Y.: X-ray photoelectron spectroscopy of $\mathrm{Er}^{3+}$ activated $\mathrm{SiO}_{2}-\mathrm{HfO}_{2}$ glass-ceramic waveguides. J. Phys. D Appl. Phys. 42, 015408 (2009)

Pechini, M.P.: Method of preparing lead and alkaline earth titanates and niobates and coating methods to form the capacitor. US Patent No. 3.330.697 (July 11, 1967)

Slooff, L.H., de Dood, M.J.A., van Blaaderen, A., Polman, A.: Erbium-implanted silica colloids with $80 \%$ luminescence quantum efficiency. Appl. Phys. Lett. 76, 3682-3684 (2000)

Stein, A., Schroden, R.C.: Colloidal crystal templating of three-dimensionally ordered macroporous solids: materials for photonics and beyond. Curr. Opin. Solid St. M. 5, 553-564 (2001)

Wiglusz, R.J., Pazik, R., Lukowiak, A., Strek, W.: Synthesis, structure, and optical properties of $\mathrm{LiEu}_{(\mathrm{PO}} \mathrm{P}_{4}$ nanoparticles. Inorg. Chem. 50, 1321-1330 (2011)

Zampedri, L., Righini, G.C., Portales, H., Pelli, S., Nunzi-Conti, G., Montagna, M., Mattarelli, M., Goncalves, R.R., Ferrari, M., Chiasera, A., Bouazaoui, M., Armellini, C.: Sol-gel-derived Er-activated $\mathrm{SiO}_{2}-\mathrm{HfO}_{2}$ planar waveguides for $1.5 \mu \mathrm{m}$ application. J. Non-Cryst. Solids 345\&346, 580-584 (2004)

Zhao, W., Hreniak, D., Boulon, G., Strek, W., Brenier, A., Yin, M., Gluchowski, P., Lukowiak, A., Wiglusz, R., Epicier, T.: Spectroscopic properties of $\mathrm{Yb}^{3+}$-doped $\mathrm{Y}_{3} \mathrm{Al}_{5} \mathrm{O}_{12}$ nano-ceramics obtained under different sintering pressures. Radiat. Meas. 45, 304-306 (2010) 